\title{
ギボウシ属植物数種の細胞学的研究 $\mathrm{V}$. マルバタマノカンザシ，トクダマギボウシ，ヒュウガ ギボウシ，ヒメヒュウガギボウシ，サザナミ ギボウシおよびイワギボウシの核型
}

\section{金 子 賢 一 郎*}

Kenichiro Kaneko: Cytological Studies on Some Species of Hosta V. Karyotypes of $H$. plantaginea, $H$. tokudama, H. kikutii, $H$. kikutii var. yakusimensis, $H$. crisupla and $H$. longipes.

Received December 9, 1968

\begin{abstract}
The chromosome numbers of the five species and one variety of Hosta ( $H$. plantaginea, H. tokudama, H. kikutii, H. crisupla, H. longipes and $H$. kikutii var. yakusimensis) were $2 \mathrm{n}=60$. The 60 chromosomes were classifiable into 30 pairs.

The karyotypes of the above species were as follows: The 30 pairs of one species and one variety ( $H$. crisupla and $H$. kikutii var. yakusimensis) could be classified into four pairs of large chromosomes, two pairs of medium ones, and 24 pairs of small ones. The karyotypes of the other four species were as follows: In three of these species (H. plantaginea, $H$. tokudama and $H$. kikutii), the chromosomes could be classified into four pairs of large chromosomes, three pairs of medium ones, and 23 pairs of small ones. In the remaining one species (H. longipes), there were four pairs of large chromosomes, four pairs of medium ones and 22 pairs of small ones.

$H$. kikutii and $H$. kikutii var. yakusimensis seem, judging from their karyotypes, to have both derived from $H$. montana.
\end{abstract}

さきに筆者 ${ }^{1,2,3,4)}$ はギボウシ属 14 種 1 変種の染色 体数执よび核型について報告した. 今回前報告につ づいて 5 種 1 变種の染色体数および核型を観察した 結果，つぎのととがわかった。すなわち、マルバタ マノカンザシ，トクダマギボウシ，ヒュウガギボウ シ，ヒメヒュウガギボウシ，サザナミギボウシおよ びイワギボウシの 5 種 1 変種の体細胞染色体数はい ずれも $2 \mathrm{n}=60$ で，それらは 2 本ずつ対をして 30 対 にわけられること，それら 30 対 の染色体の核型は 長さの相異から, 大型, 中型および小型の三群に大

* 福岡教育大学生物学教室 Department of Biology, Fukuoka University of Education, Munakata, Fukuoka, Japan.
別されるが，その詳細は種によって变異がみられる ことなどである。

本研究は上記 5 種 1 变種の染色体数抢よび核型に ついての観察結果をしめす.

\section{材料および方法}

本研究で用いられた 5 種 1 变種とそれらの採集地 はつぎのとおりである.

H. plantaginea Ascherson (マルバタマ)カン ザシ), 東京 (栽培種); H. tokudama Maekawa (トクダマギボウシ), 東京 (栽培種)；H. kikutii Maekawa (ヒェウガギボウシ), 宮崎県日向市; $H$. kikutii var. yakusimensis Maekawa (ヒメヒュ 


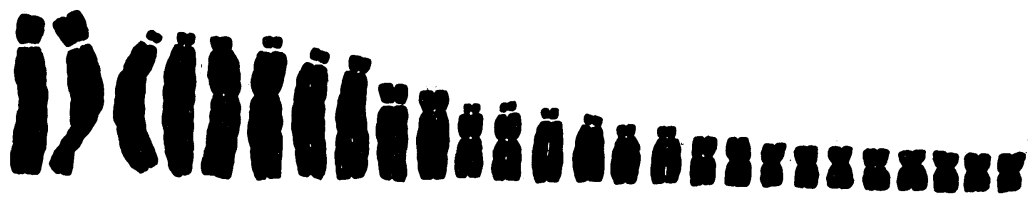

1

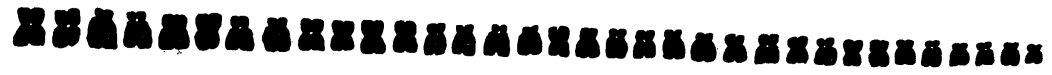



2

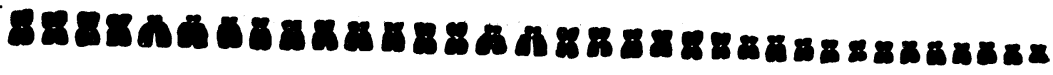

89.

3

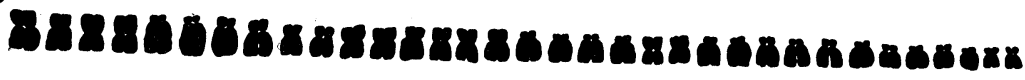

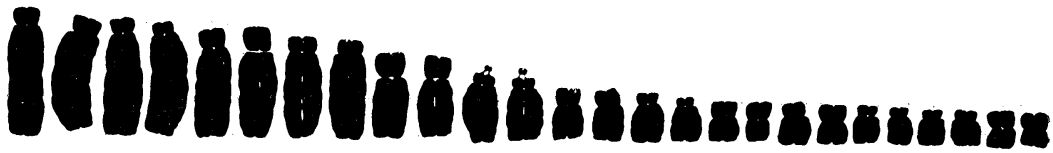

4

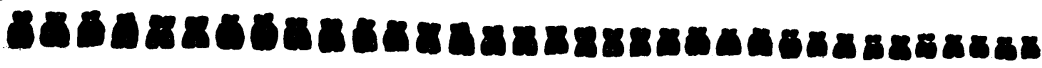

Vilinilloinonosazsozas.

5

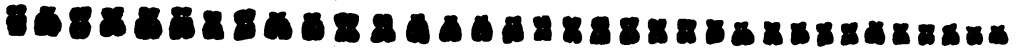

illillillonanuinanasanas

6

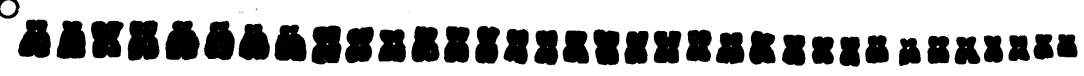

Figs. 1-6. Somatic chromosomes of Hosta. 1, H. plantaginea, $2 \mathrm{n}=60 ; 2$, H. tokudama, $2 \mathrm{n}=60 ; 3, H$. kikutii, $2 \mathrm{n}=60 ; 4$, H. kikutii var. yakusimensis, $2 \mathrm{n}=60 ; 5, H$. crisupla, $2 \mathrm{n}=$ $60 ; 6, H$. longipes, $2 \mathrm{n}=60 . \quad \times 1800$. 
ウガギボウシ), 鹿児島県屋久島；H. crisupla Maekawa (サザナミギボウシ), 東京 (栽培種); $H$. longipes Matsumura (イワギボウシ)，神奈川県 中津川.

上記の材料は本研究に際して，いずれも前川より 提供をうけたものである.

核型の観察は根端細胞において行なわれた。その 方法は前報告1)のよおである。
観 察 結 果

1. H. plantaginea マルバタマノカンザシ (Figs. $1,7)$

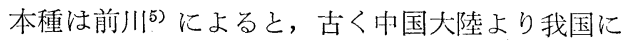
伝わり現在栽培種として各地で栽培さ机ているもの で, 本研究での株は東京で栽培のものを前川が入手 し, そのご東京大学理学部植物学教室の栽培園で栽 培されていたものである。

本種の体細胞 染色体数は $2 \mathrm{n}=60$ で，その核型は

Table 1. Measurement of somatic chromosomes of $H$. plantaginea.

\begin{tabular}{|c|c|c|c|c|c|}
\hline \multicolumn{2}{|c|}{ Chromosomes } & \multirow{2}{*}{$\begin{array}{l}\text { Length in } \mu \\
1.7+8.3=10.0\end{array}$} & \multirow{2}{*}{$\frac{\text { R. L. }}{100}$} & \multirow{2}{*}{$\frac{F(\%)}{17}$} & \multirow{2}{*}{$\frac{\text { Centromeres }}{\text { st }}$} \\
\hline 1 & 2 & & & & \\
\hline 3 & 4 & $0.7+3.5=9.2$ & 92 & 8 & $\mathrm{t}$ \\
\hline $5 s$, & $6 s$ & $3.5+5.3=8.8$ & 88 & 40 & $\mathrm{sm}$ \\
\hline 7 & 8 & $1.0+7.0=8.0$ & 80 & 13 & st \\
\hline 9 & 10 & $1.3+4.8=6.1$ & 61 & 21 & st \\
\hline $11 \mathrm{~s}$, & $12 \mathrm{~s}$ & $2.2+2.5=4.7$ & 47 & 47 & $\mathrm{sm}$ \\
\hline 13 & 14 & $0.6+3.9=4.5$ & 45 & 13 & st \\
\hline 15 & 16 & $0.6+2.9=3.5$ & 35 & 17 & st \\
\hline 17 & 18 & $1.4+1.6=3.0$ & 30 & 47 & $\mathrm{sm}$ \\
\hline 19 , & 20 & $1.1+1.4=2.5$ & 25 & 44 & $\mathrm{sm}$ \\
\hline 21 & 22 & $1.0+1.5=2.5$ & 25 & 40 & $\mathrm{sm}$ \\
\hline 23 & 24 & $0.9+1.6=2.5$ & 25 & 36 & $\mathrm{sm}$ \\
\hline 25 & 26 & 1. $0+1.4=2.4$ & 24 & 42 & $\mathrm{sm}$ \\
\hline 27 & 28 & $1.0+1.4=2.4$ & 24 & 42 & $\mathrm{sm}$ \\
\hline 29 & 30 & $0.4+1.7=2.1$ & 21 & 19 & st \\
\hline 31 & 32 & $0.8+1.3=2.1$ & 21 & 38 & $\mathrm{sm}$ \\
\hline 33 & 34 & $0.5+1.6=2.1$ & 21 & 24 & st \\
\hline 35 & 36 & $0.8+1.0=1.8$ & 18 & 44 & $\mathrm{sm}$ \\
\hline 37 & 38 & $0.8+1.0=1.8$ & 18 & 44 & $\mathrm{sm}$ \\
\hline 39 & 40 & $0.5+1.2=1.7$ & 17 & 29 & st \\
\hline 41 & 42 & $0.3+1.3=1.6$ & 16 & 19 & st \\
\hline 43 & 44 & $0.7+0.9=1.6$ & 16 & 44 & $\mathrm{sm}$ \\
\hline 45 & 46 & $0.7+0.9=1.6$ & 16 & 44 & $\mathrm{sm}$ \\
\hline 47 & 48 & $0.5+1.1=1.6$ & 16 & 31 & $\mathrm{sm}$ \\
\hline 49 & 50 & $0.6+1.0=1.6$ & 16 & 38 & $\mathrm{sm}$ \\
\hline 51 , & 52 & $0.4+1.0=1.4$ & 14 & 29 & st \\
\hline 53 & 54 & $0.7+0.7=1.4$ & 14 & 50 & $\mathrm{~m}$ \\
\hline 55 & 56 & $0.4+0.9=1.3$ & 13 & 31 & $\mathrm{sm}$ \\
\hline 57 & 58 & $0.3+0.9=1.2$ & 12 & 25 & st \\
\hline 59 & 60 & $0.3+0.8=1.1$ & 11 & 27 & st \\
\hline
\end{tabular}

R. L., Relative length. $F(\%)$ is the percentage of the short arm length to the total chromosome length. $t$, terminal; st, subterminal; $m$, median; sm, submedian. 
つぎのようであった。

60 本の体細胞染色体は 2 本ずつ 対をして 30 対に わけられ，それらは長さの相異から三つの群に大别 される.すなわち, 大型染色体が 4 対, 中型が 3 対, 小型が 23 対である. 大型染色体の 4 対 は長さが $10.0 \mu$ から $8.0 \mu$ で他の中型および小型の染色体 にくらべて著しく長く, 一次狭窄の位置は 2 対が subterminal, 1 対が terminal, 1 対が submedian でしかも submedian の1対は付随体染色体である. 中型の 3 対は長さが $6.1 \mu$ から $4.5 \mu$ までの染色 体で, それら 3 対の一次狭窄 の位置は 2 対が subterminal, 1 対が submedianでしかも後者の1対は
付随体染色体であった. 小型の 23 対は長さが $3.5 \mu$ から $1.1 \mu$ までの染色体で, それらの一次狭窄の位 置は 8 対が subterminal, 14 対が submedian, 残 り 1 対が median であった。 以上の結果は第 1 表 に示されている.

2. H. tokudama トクダマギボウシ (Figs. 2, 9) 本種は前川 ${ }^{5)}$ にると本州各地で栽培種として栽 培されているもので, 本研究での株は東京で栽培さ れていたものである.

本種の体細胞染色体数は $2 \mathrm{n}=60$ でその核型はつ ぎのようであった. 60 本の染色体は 2 本ずっ1対をな

Table 2. Measurement of somatic chromosomes of H. tokudama.

\begin{tabular}{|c|c|c|c|c|c|}
\hline \multicolumn{2}{|c|}{ Chromosomes } & \multirow{2}{*}{$\begin{array}{l}\text { Length in } \mu \\
1.4+7.6=9.0\end{array}$} & \multirow{2}{*}{$\frac{\text { R. L. }}{100}$} & \multirow{2}{*}{$\frac{F(\%)}{16}$} & \multirow{2}{*}{$\frac{\text { Centromeres }}{\text { st }}$} \\
\hline 1 , & 2 & & & & \\
\hline 3 & 4 & $0.7+7.8=8.5$ & 94 & 8 & $\mathrm{t}$ \\
\hline $5 s$ & $6 s$ & $3.6+4.1=7.7$ & 86 & 47 & $\mathrm{sm}$ \\
\hline 7 & 8 & $0.7+7.0=7.7$ & 86 & 9 & $\mathrm{t}$ \\
\hline 9 & 10 & $1.3+4.4=5.7$ & 63 & 23 & st \\
\hline 11 & 12 & $1.0+3.4=4.4$ & 49 & 23 & st \\
\hline 13 & 14 & $0.7+3.3=4.0$ & 44 & 18 & st \\
\hline 15 & 16 & $0.6+2.3=2.9$ & 32 & 21 & st \\
\hline 17 & 18 & $1.0+1.4=2.4$ & 27 & 42 & $\mathrm{sm}$ \\
\hline 19 & 20 & $0.9+1.3=2.2$ & 24 & 41 & $\mathrm{sm}$ \\
\hline 21 & 22 & 1. $0+1.1=2.1$ & 23 & 48 & $\mathrm{sm}$ \\
\hline 23 & 24 & $0.7+1.4=2.1$ & 23 & 33 & $\mathrm{sm}$ \\
\hline 25 & 26 & $1.0+1.1=2.1$ & 23 & 48 & $\mathrm{sm}$ \\
\hline 27 & 28 & $0.9+1.1=2.0$ & 22 & 45 & $\mathrm{sm}$ \\
\hline 29 & 30 & $0.8+1.1=1.9$ & 21 & 42 & $\mathrm{sm}$ \\
\hline 31 & 32 & $0.3+1.6=1.9$ & 21 & 16 & st \\
\hline 33 & 34 & $0.6+1.3=1.9$ & 21 & 32 & $\mathrm{sm}$ \\
\hline 35 & 36 & $0.7+1.1=1.8$ & 20 & 39 & $\mathrm{sm}$ \\
\hline 37 & 38 & $0.5+1.3=1.8$ & 20 & 28 & st \\
\hline 39 & 40 & $0.8+1.0=1.8$ & 20 & 44 & $\mathrm{sm}$ \\
\hline 41 & 42 & $0.4+1.3=1.7$ & 19 & 24 & st \\
\hline 43 & 44 & $0.7+1.0=1.7$ & 19 & 41 & $\mathrm{sm}$ \\
\hline 45 & 46 & $0.6+1.1=1.7$ & 19 & 35 & $\mathrm{sm}$ \\
\hline 47 & 48 & $0.8+0.8=1.6$ & 18 & 50 & $\mathrm{~m}$ \\
\hline 49 & 50 & $0.3+1.2=1.5$ & 17 & 20 & st \\
\hline 51 & 52 & $0.5+0.9=1.4$ & 16 & 36 & $\mathrm{sm}$ \\
\hline 53 & 54 & $0.6+0.7=1.3$ & 14 & 46 & $\mathrm{sm}$ \\
\hline 55 & 56 & $0.3+1.0=1.3$ & 14 & 23 & st \\
\hline 57 & 58 & $0.3+1.0=1.3$ & 14 & 23 & st \\
\hline 59 & 60 & $0.5+0.7=1.2$ & 13 & 42 & $\mathrm{sm}$ \\
\hline
\end{tabular}


して 30 対にわけられ，それらはマルバタマノカン ザシの場合と同じように長さの相異から大型染色体 が 4 対, 中型が 3 対, 小型が 23 対の 3 群に大別さ れる. 大型の 4 対は長さが $9.0 \mu$ から $7.7 \mu$ で, 一次狭窄の位置は 2 対が terminal, 1 対が subterminal, 残り 1 対は submedian で, しかも submedian の 1 対は付随体染色体である. 中型の 3 対 は長さが $5.7 \mu$ から $4.0 \mu$ までの染色体で, それ らの一次狭窄 の位置はいずれも subterminal で あった．小型の 23 対は長さが $2.9 \mu$ から $1.2 \mu$ ま でで，それらの一次狭窄の位置は大部分の染色体が subterminal かまたは submedian であった。以
上の結果は第 2 表に示されている.

3. H. kikutii ヒュウガギボウシ (Fig. 3,8)

本種は前川 ${ }^{5)}$ によと, 宮崎県に生育するとされ ている. 本研究の株は前川によって宮崎県日向市で 採集されたものの株分けである。

本種の体細胞染色体数は $2 \mathrm{n}=60$ で. それら 60 本 の染色体は上記 2 種と同じように長さの相異から大 型が 4 対, 中型が 3 対, 小型が 23 対の 3 群に大別さ れる. 大型の 4 対は長さが $11.8 \mu$ から $8.9 \mu$ まで の染色体で長さが著しく長く, それらの一次狭窄の 位置は 3 対が terminal, 残り 1 対が median にち

Table 3. Measurement of somatic chromosomes of $H$. kikutii.

\begin{tabular}{|c|c|c|c|c|c|}
\hline \multicolumn{2}{|c|}{ Chromosomes } & \multirow{2}{*}{$\begin{array}{c}\text { Length in } \mu \\
0.9+10.9=11.8\end{array}$} & \multirow{2}{*}{$\frac{\text { R. L. }}{100}$} & \multirow{2}{*}{$\frac{F(\%)}{8}$} & \multirow{2}{*}{$\frac{\text { Centromeres }}{\mathrm{t}}$} \\
\hline 1 & 2 & & & & \\
\hline $3 s$, & $4 \mathrm{~s}$ & $5.0+5.2=10.2$ & 86 & 49 & $\mathrm{sm}$ \\
\hline 5 & 6 & $0.8+9.4=10.2$ & 86 & 8 & $\mathrm{t}$ \\
\hline 7 & 8 & $0.8+8.1=8.9$ & 75 & 9 & $\mathrm{t}$ \\
\hline 9 & 10 & $1.9+5.2=7.1$ & 60 & 27 & st \\
\hline 11 & 12 & $0.5+5.5=6.0$ & 51 & 8 & $\mathrm{t}$ \\
\hline 13 & 14 & $0.7+4.9=5.6$ & 47 & 13 & st \\
\hline 15 & 16 & $1.3+1.7=3.0$ & 25 & 43 & $\mathrm{sm}$ \\
\hline 17 & 18 & $1.0+1.9=2.9$ & 24 & 34 & $\mathrm{sm}$ \\
\hline 19 & 20 & $1.2+1.5=2.7$ & 23 & 44 & $\mathrm{sm}$ \\
\hline 21 & 22 & $0.4+2.1=2.5$ & 21 & 16 & st \\
\hline 23 & 24 & $0.4+2.0=2.4$ & 20 & 17 & st \\
\hline 25 & 26 & $1.1+1.3=2.4$ & 20 & 46 & $\mathrm{sm}$ \\
\hline 27 & 28 & $0.9+1.4=2.3$ & 19 & 39 & $\mathrm{sm}$ \\
\hline 29 & 30 & $1.0+1.3=2.3$ & 19 & 43 & $\mathrm{sm}$ \\
\hline 31 & 32 & $0.3+2.0=2.3$ & 19 & 13 & st \\
\hline 33 & 34 & $0.5+1.8=2.3$ & 19 & 22 & st \\
\hline 35 & 36 & $0.6+1.3=1.9$ & 16 & 32 & $\mathrm{sm}$ \\
\hline 37 & 38 & $0.8+1.0=1.8$ & 15 & 44 & $\mathrm{sm}$ \\
\hline 39 & 40 & $0.7+1.0=1.7$ & 14 & 41 & $\mathrm{sm}$ \\
\hline 41 & 42 & $0.7+1.0=1.7$ & 14 & 41 & $\mathrm{sm}$ \\
\hline 43 & 44 & $0.3+1.4=1.7$ & 14 & 18 & st \\
\hline 45 & 46 & $0.3+1.3=1.6$ & 13 & 19 & st \\
\hline 47 & 48 & $0.7+0.9=1.6$ & 13 & 44 & $\mathrm{sm}$ \\
\hline 49 & 50 & $0.3+1.2=1.5$ & 12 & 20 & st \\
\hline 51, & 52 & $0.3+1.2=1.5$ & 12 & 20 & st \\
\hline 53 & 54 & $0.3+1.2=1.5$ & 12 & 20 & st \\
\hline 55 & 56 & $0.3+1.0=1.3$ & 11 & 23 & st \\
\hline 57 & 58 & $0.3+1.0=1.3$ & 11 & 23 & st \\
\hline 59 & 60 & $0.3+0.9=1.2$ & 10 & 25 & st \\
\hline
\end{tabular}


かい submedianでしかも付随体染色体である。中 型の 3 刘は長さが $7.1 \mu$ から $5.6 \mu$ までの染色体 で, そ秃らの一次狭窄の位置は 2 対が subterminal, 1 対が terminal であった. 小型の 23 対 は長さが $3.0 \mu$ から $1.2 \mu$ までの染色体で, それらの一次狭 窄の位置は subterminal または submedianであ。 た。 以上の結果注第 3 表に示されている.

4. H. kikutii var. yakusimensis ヒメヒュウガギ ボウシ (Fig. 4)

本種は前川に5゙よると九州地方に生育するとされ ている. 本研究での株は鹿児島県屋久島で前川が採
集したものの株分けである.

体細胞染色体数は $2 \mathrm{n}=60$ で 上記ヒュウガギボウ シのそれと同じであった，こ秃ら60本の染色体の 核型はっぎのようであった. 60 本の染色体は 2 本ず つ対をして 30 対となり，それらは長さの相異から 大型が 4 対, 中型が 2 対および小型が 24 対の 3 群 に大別されるが，それらを上記ヒュウガギボウシで の 3 群と比較すると若干相異する。すなわちヒュウ ガギボウシにおいては中型が 3 対, 小型が 23 対観 察されたが，ヒメヒュウガギボウシでは中型染色体 が 2 対で小型染色体が 24 対である.

大型染色体の 4 対は長さが $8.1 \mu$ から $6.2 \mu$ まで

Table 4. Measurement of somatic chromosomes of $H$. kikutii var. yakushimensis.

\begin{tabular}{|c|c|c|c|c|c|}
\hline \multicolumn{2}{|c|}{ Chromosomes } & \multirow{2}{*}{$\begin{array}{l}\text { Length in } \mu \\
1.0+7.1=8.1\end{array}$} & \multirow{2}{*}{$\begin{array}{l}\text { R. L. } \\
100\end{array}$} & \multirow{2}{*}{$\frac{\mathrm{F}(\%)}{12}$} & \multirow{2}{*}{$\frac{\text { Centromeres }}{\text { st }}$} \\
\hline 1 & 2 & & & & \\
\hline 3 & 4 & $0.7+6.4=7.1$ & 88 & 10 & $\mathrm{t}$ \\
\hline 5 & 6 & $1.3+5.3=6.6$ & 81 & 20 & st \\
\hline 7 & 8 & $0.8+5.4=6.2$ & 77 & 13 & st \\
\hline 9 & 10 & $1.4+3.7=5.1$ & 63 & 27 & st \\
\hline $11 \mathrm{~s}$, & $12 \mathrm{~s}$ & $0.5+3.2=3.7$ & 46 & 14 & st \\
\hline 13 & 14 & $1.0+2.2=3.2$ & 40 & 31 & $\mathrm{sm}$ \\
\hline 15 & 16 & $0.4+2.2=2.6$ & 32 & 15 & st \\
\hline 17 & 18 & $1.0+1.4=2.4$ & 30 & 42 & $\mathrm{sm}$ \\
\hline 19 & 20 & $1.0+1.3=2.3$ & 28 & 43 & $\mathrm{sm}$ \\
\hline 21 & 22 & $0.6+1.7=2.3$ & 28 & 26 & st \\
\hline 23 & 24 & $0.6+1.6=2.2$ & 27 & 27 & st \\
\hline 25 & 26 & $0.9+1.2=2.1$ & 26 & 43 & $\mathrm{sm}$ \\
\hline 27 & 28 & $0.7+1.4=2.1$ & 26 & 33 & $\mathrm{sm}$ \\
\hline 29 & 30 & $0.5+1.6=2.1$ & 26 & 24 & st \\
\hline 31 & 32 & $0.8+1.1=1.9$ & 23 & 42 & $\mathrm{sm}$ \\
\hline 33 & 34 & $0.4+1.5=1.9$ & 23 & 21 & st \\
\hline 35 & 36 & $0.6+1.3=1.9$ & 23 & 32 & $\mathrm{sm}$ \\
\hline 37 & 38 & $0.5+1.4=1.9$ & 23 & 26 & st \\
\hline 39 & 40 & $0.6+1.1=1.7$ & 21 & 35 & $\mathrm{sm}$ \\
\hline 41 & 42 & $0.6+1.1=1.7$ & 21 & 35 & sm \\
\hline 43 & 44 & $0.8+0.9=1.7$ & 21 & 47 & $\mathrm{sm}$ \\
\hline 45 & 46 & $0.7+0.9=1.6$ & 20 & 44 & $\mathrm{sm}$ \\
\hline 47 & 48 & $0.6+1.0=1.6$ & 20 & 38 & $\mathrm{sm}$ \\
\hline 49 & 50 & $0.4+1.1=1.5$ & 19 & 27 & st \\
\hline 51 & 52 & $0.4+1.1=1.5$ & 19 & 27 & st \\
\hline 53 & 54 & $0.5+1.0=1.5$ & 19 & 33 & $\mathrm{sm}$ \\
\hline 55 & 56 & $0.5+0.9=1.4$ & 17 & 36 & $\mathrm{sm}$ \\
\hline 57 & 58 & $0.5+0.9=1.4$ & 17 & 36 & $\mathrm{sm}$ \\
\hline 59 & 60 & $0.3+0.8=1.1$ & 14 & 27 & st \\
\hline
\end{tabular}


の染色体で, そ机らの一次狭窄の位置は 1 対が terminal で残り 3 対はいずれも subterminal で あり，付随体染色体は観察されなかった．中型の 2 刘性長さが $5.1 \mu$ と $3.7 \mu$ でそれらの一次狭䆣の 位置はいずれも subterminal であるが，長さが 3.7 $\mu の 1$ 対は付随体染色体であった。 小型の 24 対は 長さが $3.2 \mu$ から $1.1 \mu$ までの小さい染色体でを れらの一次狭窄の位置は subterminal または submedian であった．以上の結果は第 4 表に示さ机て いる.

5. H. crisupla サザナミギボウシ (Fig. 5)
本種は前川「「によよと本州各地に栽培種として栽 培されている. 本研究での株は前川が東京で栽培の ものを入手し, そのご東京大学小石川植物園で栽培 されていたものである.

本種の体細胞染色体数は $2 \mathrm{n}=60$ で，それらは大 型の 4 対, 中型の 2 対, 小型の 24 対の 3 群に大別 される。

大型の 4 対は長さが $8.0 \mu$ かう $6.4 \mu$ までの染色 体で, 艺机らの一次狭寉の位置は 2 対が terminal, 残り 2 対が subterminal であった。 中型の 2 対の 染色体は長さがそれぞれ 5.1 亿と. $4.5 \mu$ でそ机らの 一次狭窟の位置はいずれも subterminal であった。

Table 5. Measurement of somatic chromosomes of H. crisupula.




小型の 24 対は長さが $3.1 \mu$ から $1.2 \mu$ まででそれ らの一次狭窄の位置は subterminal が 9 対, submedian が 14 対, median が 1 対であった. 以上 の結果は第 5 表に示されている.

\section{H. longipes イワギボウシ (Figs. 6,10)}

本種は前川泉によると本州中部拈よび九州に生育 するとされている. 本報での株は神奈川県中津川で 採集され，そのご東京大学小石川植物園で栽培され ていたものである.

本種の体 細胞染色体数は $2 \mathrm{n}=60$ で，それらは 2 本ずつ対をして 30 対にわけられ，さらに光的ら 30
対は長さの相異から大型の 4 対, 中型の 4 対および 小型の 22 対の三つの群に大別される. 大型染色体 の 4 対は長さが $9.6 \mu$ から $7.2 \mu$ まで 観察され, それらの一次狭窟の位置は terminal が 2 対, subterminal が 2 対であった. 中型の 4 対は長さが $5.8 \mu$ から $4.0 \mu$ までの染色体でそれらの一次狭窄 の位置はいずれも subterminal であった. 小型の 22 対は長さが $2.4 \mu$ から $1.3 \mu$ まで観察され, そ れらの一次狭窄の位置は subterminal が 4 対, submedian が 14 対, median が 4 対であった. 以 上の結果は第 6 表に示されている.

Table 6. Measurement of somatic chromosomes of $H$. longipes.

\begin{tabular}{|c|c|c|c|c|c|}
\hline \multicolumn{2}{|c|}{ Chromosomes } & \multirow{2}{*}{$\begin{array}{l}\text { Length in } \mu \\
1.9+7.7=9.6\end{array}$} & \multirow{2}{*}{$\begin{array}{l}\text { R.L. } \\
100\end{array}$} & \multirow{2}{*}{$\frac{\mathrm{F}(\%)}{20}$} & \multirow{2}{*}{$\frac{\text { Centromeres }}{\text { st }}$} \\
\hline 1, & 2 & & & & \\
\hline 3 & 4 & $0.9+7.7=8.6$ & 90 & 10 & $\mathrm{t}$ \\
\hline 5 , & 6 & $0.7+7.7=8.4$ & 88 & 8 & $\mathrm{t}$ \\
\hline 7, & 8 & $1.2+6.0=7.2$ & 75 & 17 & st \\
\hline 9, & 10 & $1.1+4.7=5.8$ & 60 & 19 & st \\
\hline 11, & 12 & $0.9+4.2=5.1$ & 53 & 18 & st \\
\hline 13, & 14 & $0.6+4.0=4.6$ & 48 & 13 & st \\
\hline 15, & 16 & $0.6+3.4=4.0$ & 42 & 15 & st \\
\hline 17, & 18 & $1.1+1.3=2.4$ & 25 & 46 & $\mathrm{sm}$ \\
\hline 19, & 20 & 1. $0+1.4=2.4$ & 25 & 42 & $\mathrm{sm}$ \\
\hline 21 , & 22 & 1. $0+1.4=2.4$ & 25 & 42 & $\mathrm{sm}$ \\
\hline 23 , & 24 & $0.9+1.5=2.4$ & 25 & 38 & $\mathrm{sm}$ \\
\hline 25 , & 26 & $0.6+1.7=2.3$ & 24 & 26 & st \\
\hline 27 , & 28 & $0.5+1.7=2.2$ & 23 & 23 & st \\
\hline 29 , & 30 & $0.7+1.4=2.1$ & 22 & 33 & $\mathrm{sm}$ \\
\hline 31 , & 32 & $0.5+1.6=2.1$ & 22 & 24 & st \\
\hline 33 , & 34 & $0.4+1.6=2.0$ & 21 & 20 & st \\
\hline 35 , & 36 & 1. $0+1.0=2.0$ & 21 & 50 & $\mathrm{~m}$ \\
\hline 37 , & 38 & $0.8+1.0=1.8$ & 19 & 44 & $\mathrm{sm}$ \\
\hline 39 , & 40 & $0.8+1.0=1.8$ & 19 & 44 & $\mathrm{sm}$ \\
\hline 41 , & 42 & $0.9+0.9=1.8$ & 19 & 50 & $\mathrm{~m}$ \\
\hline 43 & 44 & $0.9+0.9=1.8$ & 19 & 50 & $\mathrm{~m}$ \\
\hline 45 , & 46 & $0.9+0.9=1.8$ & 19 & 50 & $\mathrm{~m}$ \\
\hline 47, & 48 & $0.7+1.0=1.7$ & 18 & 41 & $\mathrm{sm}$ \\
\hline 49 , & 50 & $0.7+1.0=1.7$ & 18 & 41 & sm \\
\hline 51 , & 52 & $0.7+0.9=1.6$ & 17 & 44 & $\mathrm{sm}$ \\
\hline 53, & 54 & $0.6+1.0=1.6$ & 17 & 38 & $\mathrm{sm}$ \\
\hline 55 , & 56 & $0.6+1.0=1.6$ & 17 & 38 & $\mathrm{sm}$ \\
\hline 57 , & 58 & $0.7+0.8=1.5$ & 16 & 47 & $\mathrm{sm}$ \\
\hline 59 , & 60 & $0.4+0.9=1.3$ & 14 & 31 & $\mathrm{sm}$ \\
\hline
\end{tabular}




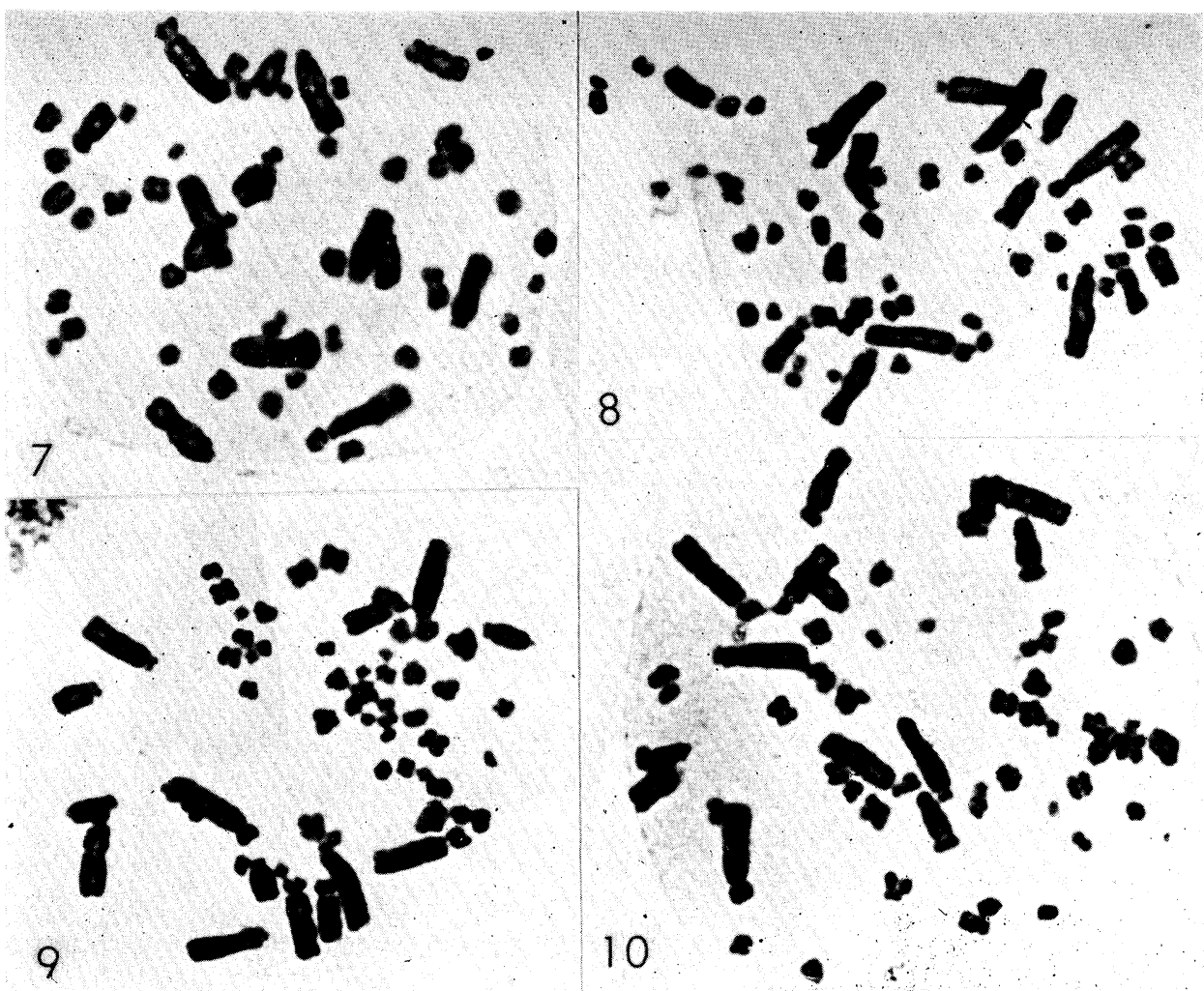

Figs. 7-10. Photomicrographs of somatic chromosomes of Hosta. 7, H. plantaginea, $2 \mathrm{n}=60 ; 8, H$. kikutii, $2 \mathrm{n}=60 ; 9$, H. tokudama, $2 \mathrm{n}=60 ; 10, H$. longipes, $2 \mathrm{n}=60 . \quad \times 1400$.

考 察

ギボウシ属の染色体数についてはすでに筆 者 $1,2,3,4)$ は 14 種 1 変種について報告し, それらのう ち 12 種においては $2 \mathrm{n}=60,1$ 種 1 変種で $2 \mathrm{n}=90$, 残り 1 種では $2 \mathrm{n}=120$ で本属の染色体基本数は $\mathrm{X}=$ 30 であることを示した. また本属の染色体数につい ては, さきに明峯(6), 佐藤7), 保井 ${ }^{8)}$ 等によって 9 種 が観察がなされ，それらのうち 8 種で $2 \mathrm{n}=60,1$ 種 で $2 \mathrm{n}=90$ と報告されている.

本研究で筆者が明らかにした 5 種 1 変種, マルバ タマノカンザシ, トクダマギボウシ，ヒュウガギボ ウシ，ヒメヒュウガギボウシ，サザナミギボウシの 染色体数もすべて $2 \mathrm{n}=60$ であるから,さきに筆者 ${ }^{1}$ が示したように本属の染色体基本数は $\mathrm{X}=30$ とし て間違いはないと考える。

本属植物の核型については,さきに筆者》 はオオ
バギボウシ，コバギボウシ，ナガサキギボウシ等で は 60 本の染色体が 30 対となりそれら 30 対 は大型 の 4 対, 中型の 2 対, 小型の 24 対にわけられ, しか も大型染色体の 4 対の一次狭窄の位置は terminal かそれに近い subterminal にあり, 中型染色体の 2 対のらち 1 対は付随体染色体であることを観察し, これをギボウシ属の基本的核型の一つとタなした. また筆者および前川9 はカンザシギボウシが産地に よって核型に変異がみられ，その変異の特性は 4 対 の大型染色体の一次狭察の位置にみられることを明 らかにし，それらの核型变化について三段階の変化 過程を示した。

本研究でのマルバタマノカンザシの核型をみると， 大型が 4 対, 中型が 3 対，小型が 23 対に大別され， 4 対の大型のうち 1 対は一次狭窄を submedian に もつ付随体染色体である.この submedian の 1 対 はさきに筆者および前川 ${ }^{9)}$ が示した核型の变化過程 
から考察すると terminal かまたはそれにちかい subterminal に一次狭窄をもつ大型染色体から導 かれたものであるう。中型染色体は 3 対夕られたが, これはさきに示した本属の基本的核型と相異する. すなわら，基本的核型では中型染色体は 2 対で，し かもそれらのうら 1 対は付随体染色体であるが，本 種では中型が 3 対で, そのうちの 1 対は付随体染色 体であるが残り 2 対はいずれも subterminal に一 次狭窄をもつ染色体である。このように大型が 4 対,

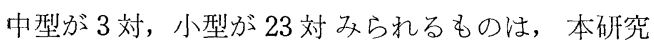
で取り扱った 5 種 1 変種のうち, 上記マルバタマ， カンザシのほか，ヒュウガギボウジ，トクダマギボ ウシにおいても観察され，さらに大型が 4 対，中型 が 4 対，小型が 22 対のものがイワギボウシでみら れたが，それらの核型の詳細注種によって相異がみ られた。このように本研究で取り扱った 5 種 1 变種 においては中型および小型染色体の数および形態に

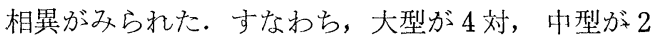
対, 小型が 24 対のほかに, 大型が 4 対, 中型が 3 対，小型が 23 対のものおよび大型が 4 対, 中型が 4 対，小型が 22 対のものがみられることが明らかに なっだ。このような中型および小型染色体にみられ る変異がいかにして導かれたものであるかはいまの ところ明らかではない。この閣題の解决汢こえごの 研究の結果から明らかにしたい.

つぎにヒュウガギボウシとヒメヒェウガギボウシ の核型を比較すると，ヒュウガギボウシはすでに示 したように大型染色体が 4 対，中型が 3 対，小型が 23 対夕られ，4対の大型染色体のらち一次狭窄を submedian にもつ1対注付随体染色体であるが， ヒメヒュウガギボウシはさきに筆者1 ${ }^{1}$ が示した本属 の基本的核型を示している.すなわち, 30 対の染任
体は大型が 4 対，中型が 2 対，小型が 24 対に大別 され, 4 対の大型染色体の一次狭䆶の位置はterminal かまたはそれに近い subterminal にあり，中型の 2 対のうち 1 対は付随体染倡体てある. この両者の 核型のうち，大型の 4 対について，さきに筆者およ び前川 ${ }^{9)}$ が示した核型変化の過程から考えると，ヒ メヒュウガギボウシでは付随体染色体は観察できな いが，ヒュウガギボウシでは付随体染色体がみられ ることからみて，前者は後者より祖型にちかい核型 をもつものと考えられる。ささに外部形態掞よび核 型からみて，ヒュウガギボウシの 1 対の付随休染色 体はオオバギボウシの大型の 1 対から導かれたもの であろう。またヒメヒュウガギボウシの核型がオオ バギボウシのそれとよく一致することからして，ヒ メヒュウガギボウシも执らくオオバギボウシから 分化したものと考える.

終りに貴重な材料を提供され，かつ有益な珋教示 を賜った東京大学教授前川文夫博士に深謝する。

\section{文献}

1) Kaneko, K., Bot. Mag. Tokyo $79: 131$ (1966).

2) - ibid. 81:267 (1968).

3) —, ibid. $81: 396$ (1968).

4) —, ibid. 82: 32 (1969).

5) Maekawa, F., J. Fac. Sci. Tokyo Imp. Univ. 5 : 317 (1940).

6) Akemine, T., J. Fac. Sci. Hokkaido Imp. Univ. 5 : 25 (1935).

7) Sato, D., Bot. and Zool. 3: 1025 (1935).

8) Yasui, K., Cytologia 6: 484 (1935).

9) Kaneko, K. and Maekawa, F., J. Fac. Sci. Tokyo Univ. 10: 1(1968). 